WANG Fengbin, JIANG Hong

\title{
Innovation paradox and ambidextrous organization: A case study on development teams of air conditioner in Haier
}

\author{
(C) Higher Education Press and Springer-Verlag 2009
}

\begin{abstract}
While knowledge exploration and exploitation represent two distinct activities requiring corresponding organizational arrangements, new product development calls for a dynamic combination of the two. Based on a systematic review of the paradox between knowledge exploration and exploitation and various resolving strategies, this research extends the construct of organizational ambidexterity from dual structure to ambidextrous capabilities, and suggests a dialectical method for reconciling this paradox at lower organizational levels. Based on a case study on the development teams of air conditioner in Haier, we find that ambidexterity is a multi-level construct existing not only at the organization level but also at lower levels such as teams and individuals like model managers.
\end{abstract}

Keywords new product development, innovation, ambidextrous organization, dual structure, knowledge exploration, knowledge exploitation

摘要 新产品开发作为企业自主创新活动的一种重要形式, 是知识探索与知识利用 有机结合的过程。在对二者悖论关系及其处理方略进行系统文献综述的基础上, 将 两栖组织的定义从 “二元结构”、“二面性结构” 伸展到 “两栖能力”, 试图在较低的 组织层次上回答如何辩证地解决二者看似矛盾实则可统一的关系。在对海尔空调开 发团队的成员构成及异质性知识组合案例分析后, 得出的结论是, “两栖” 不仅是组 Translated and revised from Jingji Guanli 经济管理 (Economic Management), 2008, (11): 44-49 and Jingji Lilun yu Jingji Guanli 经济理论与经济管理 (Economic Theory and Business Management), 2008, (2): 51-57

WANG Fengbin $(\triangle)$

School of Business, Renmin University of China, Beijing 100872, China

E-mail: wfengbin@ruc.edu.cn

JIANG Hong

School of Business, Renmin University of China, Beijing 100872, China

Email: lesta.jiang@ruc.edu.cn 
织层面的构念, 而且可以是团队乃至像 “型号经理” 这样的个体员工层面的构念。

关键词 新产品开发, 创新, 两栖组织, 二元结构, 知识探索, 知识利用

\section{Introduction}

How do organizations adapt to the rapidly changing environment? Conventional ecological wisdom suggests that most established organizations are inclined to suffer from various inertias and spin-off is frequently taken as a measure to survive environmental changes. However, recent research reveals that some large firms do adapt well to shifting contexts through continuous and effective innovation. How does this occur? The emerging studies fall into two camps: (1) Those focusing on assigning, adapting and aligning responsibilities to separate organizational units (e.g., divisions or subsidiaries), which are coordinated and integrated by top management teams (Tushman and O'Reilly, 1996; Smith and Tushman, 2005), and (2) those dealing with simultaneous exploration and exploitation within the same organizational units through cultivating ambidextrous contexts (Gibson and Birkinshaw, 2004). Underlying the choice is a fundamental debate over whether it is practical to achieve ambidexterity at a sufficiently low organizational level so that the whole firm can be equipped with "ambidextrous capabilities" for long-term success. However, the extant literature provides few insights to this prerequisite question.

As an explorative study to justify lower-level ambidexterity achieved by involving ambidextrous actors in innovation processes, this research differs from the extant literature in two ways. First, the level of analysis is lowered from firms as a whole or business units to new product development teams and their core members. Second, the research focus is no longer macro-level forces such as strategic integration via top management teams or ambidextrous context establishment, but micro-level factors such as composition and actions of new product developers.

New product development (NPD) has long been regarded as one of the most important activities necessary for firms to survive highly competitive environments. Generally speaking, NPD process can be divided into two phases: development of new product concepts, in which exploration of new knowledge prevails; and the following detailed design and manufacturing, in which exploitation of existing knowledge is mostly concerned. Although exploration and exploitation are widely regarded contradictory, effective innovations require dynamic combination of the two (March, 1991; Daft, 2004; Zhang and Li, 2006). Therefore, firms seeking for better adaptation to highly competitive and dynamic 
environment inevitably need the so-called "ambidextrous capabilities", namely capabilities to simultaneously perform two different things, i.e., exploration and exploitation.

Based on a case study of NPD teams in Haier's air conditioner sector, this research aims to disclose whether ambidexterity can be achieved at lower organizational levels such as teams and individuals, how team-level and individual-level ambidexterity can be realized, and how the dilemma between explorative and exploitative activities is resolved by cultivating lower-level ambidextrous capabilities. We will first review the literature on the paradox in innovation process as well as its different resolving strategies. It is found that of all the three possible strategies, previous research paid little attention to possibilities of resolving this paradox by reconciling exploration and exploitation. Consequently, we recommend the reconciling perspective as a new alternative for paradox solution and hereby extend organizational ambidexterity from "dual structure" to "ambidextrous capabilities". Since this kind of capabilities reside not only at the organizational level but also at lower-level units (teams composed of diversified developers) and even some special individual actors ("model managers" in the Haier case), thus organizations are capable of achieving ambidexterity at a sufficiently low organizational level. Finally, in-depth investigations of NPD teams in Haier's air conditioner sector exhibit how ambidextrous capabilities of lower-level actors were cultivated and facilitated to reconcile the dilemma between exploration and exploitation.

\section{Paradox in innovation process and corresponding solutions}

NPD, like any other innovations, is an integrated process of new idea development and implementation. According to March (1991), the former represents exploration of new knowledge and the latter emphasizes exploitation of existing knowledge. The two distinct but indispensable activities bring respectively "variance-increasing effects" (McGrath, 2001) and "selective retention" (Dopfer, 2004), indicating that effective innovation involves a paradox between creativity and efficiency (Gassmann et al., 2006; Perez-Freije and Enkel, 2007).

Contingency theory is now prevalent in dealing with this paradox, and researchers emphasize the necessity for firms to make "either/or" choices between exploration and exploitation and corresponding structural arrangements according to their own contingent determinants (e.g., industrial dynamism). For instance, it has been widely accepted that organic structures are conducive to 
achieving intended goals or stimulating new ideas, while mechanistic ones to improve efficiency (Kedia et al, 1992; Hoyt and Geroff, 1999; Daft, 2004). While the contingency perspective indicates exploration or exploitation is exclusive to each other and cannot be achieved within the same unit, some researchers suggest a compromising way to sacrifice either exploration or exploitation to some degrees in exchange for more of the other. Nevertheless, the two perspectives assume impossibility for lower-level organizational actors to rank high in both exploration and exploitation at the same time. However, our findings suggest an alternative strategy besides the "either/or" choice and compromising (as shown in Fig. 1), which enables low-level organizational actors to reconcile the paradox and score high in both dimensions simultaneously.

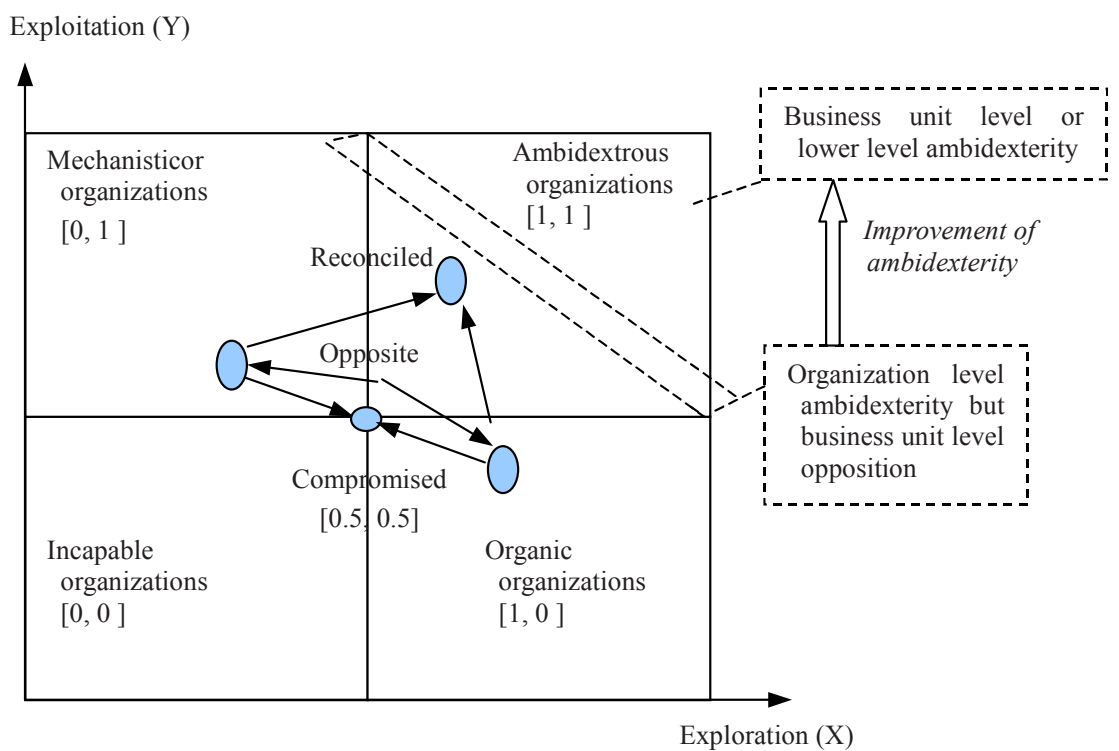

Fig. 1 Solutions to paradox

\section{1 Opposite or contingent alternatives}

Exploration is traditionally separated from exploitation by setting up differentiated units. This rationality can be explained by contingency theory that dual structural designs for innovation are contingent on special environmental contexts. Perez-Freije and Enkel (2007) proposed that introducing such contingent determinants as industrial dynamism enables firms to adopt different relational archetypes for different business units. Although contingency perspective permits co-existence of intrafirm opposites, the two can not get 
reconciled at business unit level. While newly-established units pursuing exploration are expected to be organic $([0,1]$ in Fig. 1), existing units pursuing exploitation tend to be mechanistic ([1,0] in Fig. 1), which raises an inevitable "either/or" choice for lower-level actors within the focal organization.

\subsection{Compromising strategy}

Organizations may also grasp the tensions between exploration and exploitation by establishing a portfolio of the two ([0.5, 0.5] in Fig. 1). In this portfolio, increase in one dimension is and can only be achieved by decrease in the other, though changes may not be in proportion due to nonlinear effects. This compromise means that actors have to make concessions in both dimensions in order to reach an expected balance. Many large firms in need of innovations usually replace their previous mechanistic structures with organic ones, such as replacing a large amount of existing rules with a brief statement of organizational vision, but this de-bureaucratic transformation does not necessarily bring expected organic features necessary for innovative capability improvement. The underlying reason is that effective innovations generally result from "organized chaos" (Daft, 2004) rather than linear aggregate of semi-mechanical and semi-organic. In other words, $0.5 \mathrm{X}$ plus $0.5 \mathrm{Y}$ does not definitely make 1 .

\subsection{Reconciled strategy}

The third option to cope with paradoxes is to reconcile two seemingly inconsistent statuses from the viewpoint of "Yin" and "Yang", each of which appears to be the antithesis of the other but at the same time dialectically interdependent. Ju $(2003,2007)$ argued that duality of Yin and Yang also performs in management, and can be facilitated to resolve the paradox of exploration and exploitation. For instance, Zhang and $\mathrm{Li}$ (2006) found that neither explorative nor exploitative pattern could bring about satisfactory performance. Only organizations ranking high in both and coordinating them well could exhibit exact ambidexterity, or all-level ambidexterity.

Organizational ambidexterity was firstly introduced by Duncan (1976) but did not draw much attention until Tushman and O'Reilly (1996) published their prestigious paper Evolution and Revolution: Mastering the Dynamics of Innovation and Change. Research on ambidextrous organization have been burgeoning ever since, yet the majority focus on pros and cons of ambidextrous organizations at the firm level and spare little attention to lower-level analysis which may actually imply a lot on how to establish ambidextrous capabilities. For example, Kang et al. (2007) examined the relational archetypes between key employees and their internal partners (i.e. other intra-organizational employees) as well as external ones (i.e. cooperators in alliances), and revealed how 
packaged human resource management practices help to develop certain relational archetypes as expected. In spite of the inherent either/or thinking which recommends managers to make an exclusive choice between exploratory and exploitative learning, between two relational archetypes, and between corresponding packages of human resource management practices, they emphasized that all the key employees need to establish relationships with internal or external partners (Kang et al., 2007). This, together with some previous research on the business-unit-level ambidexterity (Benner and Tushman, 2003), reminds us to pay special attention to ambidextrous capabilities of lower level actors rather than residing solely on organizational-level dual structures.

\section{From dual structure to ambidexterity}

Previous research indicates that firms are able to simultaneously exhibit mechanistic features to ensure organizational efficiency and organic features to ensure creativity by employing "dual structures" (Duncan, 1976). And the two seemingly conflicting features are generally coexistent at the whole organization level. Firms with "dual structures" usually set up specialized innovative units concentrating on explorative tasks. These units are organized organically so as to promote development of new ideas and new technologies, while other units which are designed to implement those new concepts tend to capitalize mechanistic structures to improve efficiencies. Nonaka (1994) and Nonaka and Takeuchi (1995) found that whenever a new stage in technology cycle is coming, large Japanese corporations such as Canon and Honda would set up "internal incumbents", that is, autonomous teams composed of relatively younger staffs and focused on discontinuous innovations. These internal incumbents are often spatially separated from existing organizational units in case of possible inhibitions from established rigidities (Tushman and O'Reilly, 1996; Shi and Cao, 2006).

Much of the prior literature argues that dual structures can facilitate simultaneous incremental and radical innovations by assigning the former task to established units while the latter to other self-contained units distinct from the established ones. This separation, however, produces inconsistence not only in capabilities and structures but also in cultures (Duncan, 1976; Tushman and O'Reilly, 1996; Yuan, 2001; Zhang and Chen, 2005; Zhang, 2006; Li, 2006). Thus, suitable mechanisms must be in place to coordinate these pretty different units and to prevent their inconsistencies turning into contradictions. It is suggested that organizations with dual structures must rely on top management in centralized integration (Tushman and O'Reilly, 1996, 1997; O'Reilly and 
Tushman, 2004), strategic integration (Benner and Tushman, 2003), or strategic conflict management (Smith and Tushman, 2005). Separated exploratory units can be entitled to pursue their own procedures, structures and cultures but must be guided consistently by top management. Accordingly, top management teams in large firms must be capable enough to integrate spatially separated explorative and exploitative units for the purpose of balancing short-term efficiency and long-term innovation.

However, top-management-led integration is a kind of top-down process, reflecting the logic of centralized management, which is to some extent anti-innovation. Thus some researchers tried to resolve innovative paradoxes by adding cross-temporal possibilities to structural considerations, namely switching structures (McDonough and Leifer, 1983; Daft, 2004) in which personnel responsible of routine tasks can change their roles and act as innovators whenever needed. NUMMI, a California branch of Toyota, created an independent cross-functional institution named "Navigator Team" to design assembly processes of cars and trucks. Whenever new-style automobiles are successfully put into large-scale production, team members will return to their former units and continue with routine work. A similar case can be found in an Ohio-based construction materials manufacturer. It sets up more than 150 temporary teams, of which members come from different units. All the members are working in an organic way (such as brainstorming) during the teamwork period to encourage new ideas on how to improve product performance, and then return to their own units at the end of the five-day teamwork. In such "switching structures", all the team members alternate between explorative and exploitative roles, exhibiting cross-temporal separation but overall balance of exploration and exploitation over time. Siggelkow and Levinthal (2003) argued that temporary decentralization followed by reintegration, or an initial phase of exploration enabled followed by cross-unit refinement and coordination, can lead to higher performance than purely centralized or decentralized organizational form. However, they do not make clear how to achieve the switching role over time, and cross-temporal shifts in the cycle of "mechanistic-organic-mechanistic" are not that easy due to structural inertias.

Given the difficulties of role shifts in switching structures or of central integration in dual structures, Gibson and Birkinshaw (2004) suggested a day-to-day balance between innovative and routine activities by developing organizational ambidexterity through business-level ambidextrous contexts establishment, which is also termed as contextual ambidexterity (Zheng, 2007). Gibson and Birkinshaw (2004) classify these contextual factors into (1) "performance management context" which represents a combination of discipline and stretch, and (2) "social context" which represents a combination of support 
and trust. While dual structure or switching structure brings about only organization-level ambidexterity, a Yin-Yang balance between a pair of hard elements (discipline and stretch) and a pair of soft elements (support and trust) facilitates business-unit ambidexterity through cultivation of ambidextrous contextual features. Accordingly, ambidexterity, which is oriented towards higher business-unit performance, is a sort of contextual capabilities (i.e. alignment and adaptability) stemming from interactions of Yin and Yang.

Whenever ambidextrous contexts are established, everyone in business units is influenced, hence the aggregation of individual behavior will mirror ambidextrous business-unit features and perform as autonomous ambidextrous actors. However, Gibson and Birkinshaw (2004) still leave unanswered the problem how contextual ambidexterity can be successfully established in practice through combination of "performance-management context" and "social context" despite of their imported concept of Yin-Yang. Accordingly, we aim to explore further how mutually supplemented heterogonous factors interacted to develop lower-level employees' ambidextrous capabilities in the following case study on Haier.

\section{Research Method}

Qualitative case study was chosen as our method to arrive at an encompassing view of ambidexterity at lower organizational levels. Concerns of external validity are traded off against opportunities to gain insights into those phenomena as yet incompletely documented. After some in-depth first-hand field studies, observations at Haier's air conditioner development practices, our focal firm, were effectively focused on the strategic use of business units as a means of achieving lower-level ambidexterity to adapt with rapidly coevolving markets and technologies.

\subsection{Research setting}

This research was carried out in Haier, a Qingdao-based Chinese company and the third largest manufacturer of white household appliances in the world. Haier has been pursuing organizational transformations aimed at a networked structure and a reengineered business process ever since the implementation of international strategy in 1998. Its global turnover reached as high as 103.4 billion Yuan or 12.8 billion dollars in 2005. As a business unit which catches a great portion of the total turnover, the air conditioner sector in Haier was selected to be the spot of our field studies. Particularly, its new product development teams led by so-called "Model Managers" were selected as the cross-level units of observation. 
The air conditioner development section of Haier was established in 1991 and concentrated on in-house $R \& D$ of various home air conditioners ever since. Haier is now a global provider with a maximum range of home air conditioners, including window types, wall types, cabinet types, portable types and bulkhead types. With its production capabilities of 10 million sets of home air conditioners annually, Haier is now competing in 137 countries. Moreover, it is the first and the only Chinese firm which won the IF Industrial Design Prize until 2005, a prize that usually comes to the best industrial designs all over the world. And its patent of "health air purifying" has set a dominant healthy standard in Chinese air conditioner industry. The firm not only topped on sales in domestic market with a market share of over $21 \%$ but also became the largest brand in the home air conditioner market of North America in 2005.

\subsection{Data collection}

Data collection for this case study started early in 2000. At that time, Haier invited a number of experts to its seminars to discuss its on-going "market-chain-based business process reengineering". As one of those experts involved, the first author was attracted by Haier's reform and intended to do a longitudinal case study on the growing company to map out its strategic and organizational transformation. In the following two years, two MBA students supervised by the first author accomplished their dissertations using the data from Haier's market-chain reforms. Three years later, a formal research team was established and two rounds of interviews were carried out in the beginning of 2006 and in the summer of 2007. The interviews were typically 30 to 60 minutes in length, and some informants were interviewed more than once.

In accompany with the field studies, we conducted a thorough search on journal publications and public company documents, including Haier's monthly newspaper Haier People (2004-2006) as well as related materials from new product development sections and manufacturing divisions. We came to notice that the organization of air conditioner development teams in Haier was evolving towards a kind of "result-oriented" SBUs (strategic business units). ${ }^{1}$ Hence we initiated a survey of financial archival data in the mid 2006 to collect revenue and profit distribution data between the NPD teams and its hierarchical-linked Product Sector as well as the profit sharing data among team members. All in all, the multi-sourced research process helps improve the reliability of our

\footnotetext{
${ }^{1}$ The concept of SBUs employed in Haier refers to those agents (individuals or teams) with initiatives and abilities of autonomous innovations and responsible for their own performance. The term should be regarded different from that used in GE in 1970s which usually referred to business units at division level or above as SBUs.
} 
subsequent inductive analysis.

\section{Haier's market-chain reform and its NPD teams motivated by SBUs system}

\subsection{Market-chain reform in Haier: Decomposition of business processes ${ }^{2}$}

In order to implement the targeted internationalization strategy, Haier carried out a company-wide business process reengineering based on market-chain reform at the end of 1998, aiming to change corporate structure into an architecture comprised of core value-adding processes (including "order creation" in the charge of NPD teams and "order acquisition" in the charge of Product Managers, who are located within Product Sectors) and several supporting processes. The key task of core process units is to create and acquire orders from domestic and foreign markets in order to earn incomes from satisfied customers, whereas the supporting process units are supposed to provide resources or services to core process units as internal customers. These process modules are linked together via the newly-installed "market-chain" relationships.

\subsection{SBUs in Haier: Autonomous innovative agents}

Outputs in terms of volume used to be the only interface standard between R\&D departments and product divisions before market-chain reform in Haier, which caused a widely-spread problem that R\&D departments were seriously shielded from market demands. In the initial stage of market-chain reform, Haier introduced an internal pricing system to calculate the profits made by $R \& D$ departments which were regarded as quasi-companies. That is, $R \& D$ departments would negotiate with product divisions to set up an agreed ratio of profit sharing. On the basis of the previous-recorded profits added by new product development activities, and multiplying this by the agreed ratio, R\&D departments got payments from product divisions.

In May 2002, Haier introduced the "result-oriented" SBUs incentive systems into product development. The multiplicand for NPD teams was reset as profits from new product development activities minus the breakeven number. Hence market performance of newly developed products, which is co-evaluated by

\footnotetext{
${ }^{2}$ For detailed information about market-chain reengineering in Haier, please refer to Wang et al., The Formation and Operation of Modular Organization: A Case Study on Haier's "Market Chain" Reform, Management World, 2008, (4): 122-139, or Frontiers of Business Research in China, 2008, 2(4): 621-654.
} 
Business Promotion Sector, Capital Flow Sector and After-sale Service Department (renamed Customer Service Company later) becomes the basic source of incomes of the NPD teams, and the process-based economic connections are included which promotes R\&D employees to take the whole development process into consideration until expected market performance is realized rather than just focused on technical advancement. This system assigns the end-to-end process-based responsibility to every NPD teams and their managers (Model Managers) to ensure of their concerns of the whole development process from new concept development to market value realization and finally to renewal of the kind of products.

When the system of SBUs was first introduced, new model developers were required to take charge of the entire new product development process including information collection, product planning, industrial design, development and design of product architecture and module-level components, test of product performance, trial production, introduction to markets and promotion, track following, and quality improvement. Meanwhile, they could share a ratio of net profits when the sales of new products surpass the expected volume at the breakeven point. But the ratio would decrease by $10 \%$ per month in the following 18 months after the new product's introduction to markets, and gradually dropped to zero.

In 2005, taking the consideration that measurements of market performance vary across different types of products, Haier further divided new products into three classes, namely "exotic flowers", "common grass" and "rare trees", and implemented corresponding profit sharing plans. Those R\&D personnel working on "exotic flowers" and aiming at profit making are entitled to obtain profit-based payments only when both accomplished profits and sales volume surpass previously agreed numbers. As for those in charge of "common grass" with the aim to increase sales, payments are sales-based as long as they are able to keep profit margins and sales volumes at an expected level. And for those in charge of "rare trees", things are pretty different. Since the products under their development may be completely new series with advanced technology, their effects are mainly long-term without instant profits growing. Therefore, in order to encourage those developers of long-lasting profitable potentials to catch the latest related technologies with the aim of maintaining the corporate market position in the future, Haier changed its policies and rewarded their efforts of sowing for future.

This differentiated incentive system enables R\&D personnel in Haier to balance current market demands and creation of future market. Under the economic pressure from market-chain reform, each SBU in various product sectors (Home Air Conditioner (HAC) Sector chosen as our focal case is just one of them) is oriented towards market targets and intrafirm marketalized relationships took place of former system of functional tasks and superiors. 
Zhang Ruimin, CEO of Haier Ltd., made an exposition of the advantages of SBUs system as follows: "Decision makers (superiors) provide market space and resources platform (i.e. existing conditions, advanced information, problem solving methods and supporting processes), while SBUs make innovative efforts according to particular customer complaints, and are motivated by customer satisfaction. Loyalty of customers is the mental side of motivation, while profit sharing of market performance is physical."

Guided by the concrete strategic targets, the goals of SBUs are to "grab resources, create orders, and add values". For instance, when two different types of fridge are designed using the same components but only one was successful in meeting market demands and creating expected profits, the model manager of the profit-creating type will receive high payments while the other one will get no reward for wasting limited resources.

Based on this result-orientated motivation system illustrated above, salaries of Product Managers (in charge of order acquisition) and Model Managers (in charge of order creation) in Haier depend almost completely on market performance of the products under their charge. What is more, the SBUs system applies to not only business units in core and supporting processes, but also managers at almost every level in the corporation in order to encourage them to perform creatively. Take the example of the SBU salary system for managers at all levels, the formula below is used to calculate their monthly salaries in Haier.

Monthly salary of SBU (for managers) $=$ Basic salary + Profit sharing - Loss

All managers in the SBUs system are classified into Grade-S (Product Sector directors), Grade-B (R\&D Department directors) or Grade-U (Model Managers inside the R\&D departments). Each group is further divided into three levels, namely high, medium and low according to the market scale they serve, and each level is then classified into three sublevels on the basis of the level of market risks. Therefore, there are in total 27 sublevels of basic salaries and a SBU's salary, which is directly linked with the market value created. Such a comprehensive system of SBUs has been successfully established in Haier, encouraging all SBUs to operate innovatively as active agents for creating and serving markets. And it is just in this sense that Haier refers to its new system as "all employees are SBUs". Moreover, similar to the naming of Grade-U product development managers as "small" Model Managers, Haier entitles Grade-B and Grade-S managers "medium" and "large" Model Managers respectively.

\subsection{Composition of NPD teams and cross-functional linkages}

To take end-to-end responsibilities for new product development does not mean that a model manager should be involved in everything related, instead (s) he 
may obtain various resources from other business units to establish a result-oriented, partly virtual R\&D team. Motivated by market performance, new product developers in Haier recognize that they should be able to integrate various resources, regardless of whether they are within or outside their teams, and key developers in NPD teams in Haier try to improve their coordination and communication skills to facilitate boundless cooperation within a SBU team. However, how can a high-performance NPD team be set up whenever needed? The former function-based organization structure seems not a good answer. Instead, Haier's R\&D personnel and project teams are required to compete for resources to support their own projects rather than to depend on superiors to assign new projects and allocate needed resources to them.

As one of the most competitive product sectors in Haier, the Home Air Conditioner Sector places qualification requirements on member selection for its NPD teams. As shown in Table 1, a NPD team of air conditioner commonly comprises the following two types of members: a) core members, or model developers, including a model manager ${ }^{3}$ who acts as project leader, one or two model planners and several module developers; b) R\&D assistants, who contribute in back-up activities, industrial design, product certification, printing materials preparation, experiment, trial production, etc. Core members and R\&D assistants usually share respectively $65 \%$ and $35 \%$ of the total team profits.

Table 1 Composition of NPD teams and qualifications of members

\begin{tabular}{|c|c|c|}
\hline \multicolumn{2}{|c|}{ Composition of teams } & sonal qualifications of team members \\
\hline \multirow[t]{3}{*}{$\begin{array}{l}\text { Model developers } \\
\text { ( } 65 \% \text { of team- } \\
\text { profits) }\end{array}$} & Model manager & $\begin{array}{l}\text { Junior college graduators or above, two-year } \\
\text { or more tenure, familiar with new product } \\
\text { development process, majoring in cooling, } \\
\text { heating and ventilating, mechanical or elec- } \\
\text { trical engineering, with strong communica- } \\
\text { tion and coordination skills }\end{array}$ \\
\hline & Model planners & $\begin{array}{l}\text { Junior college graduators or above, two-year } \\
\text { or more tenure, familiar with new product } \\
\text { development process, majoring in cooling, } \\
\text { heating and ventilating, mechanical or ele- } \\
\text { ctrical engineering, [with communication } \\
\text { and coordination skills]* }\end{array}$ \\
\hline & Module developers & $\begin{array}{l}\text { Junior college graduators or above, two-year } \\
\text { or more tenure, familiar with new product } \\
\text { development process, majoring in cooling, } \\
\text { heating and ventilating, mechanical or elec- } \\
\text { trical engineering }\end{array}$ \\
\hline
\end{tabular}

(To be continued)

\footnotetext{
${ }^{3}$ None of the model managers in Haier is granted with a life-long position. This temporary title always comes to those R\&D personnel who pioneer in discovering customer demands, finding out effective solutions and being permitted to initiate projects for their ideas.
} 
(Continued)

\begin{tabular}{|c|c|c|}
\hline \multicolumn{2}{|c|}{ Composition of teams } & ersonal qualifications of team members \\
\hline \multirow[t]{3}{*}{$\begin{array}{l}\text { R \& D Assistants } \\
(35 \% \text { of team- } \\
\text { profits })\end{array}$} & Back-up Managers & $\begin{array}{l}\text { Junior college graduators or above, two-year or } \\
\text { more tenure, familiar with new product } \\
\text { development process, majoring in cooling, } \\
\text { heating and ventilating, mechanical or elec- } \\
\text { trical engineering, with communication and } \\
\text { coordination skills }\end{array}$ \\
\hline & $\begin{array}{l}\text { Industrial Designers, } \\
\text { other personnel } \\
\text { for product certi- } \\
\text { fication and prin- } \\
\text { ting materials }\end{array}$ & $\begin{array}{l}\text { Junior college graduators or above, one-year or } \\
\text { more tenure, familiar with new product } \\
\text { development process }\end{array}$ \\
\hline & $\begin{array}{l}\text { Experimenters, } \\
\text { Trial producers }\end{array}$ & $\begin{array}{l}\text { Technical secondary school graduators or } \\
\text { above, familiar with new product develop- } \\
\text { ment process, with forkman driving and } \\
\text { welding skills }\end{array}$ \\
\hline
\end{tabular}

Note: ${ }^{*}$ Contents in square brackets are added according to interviews.

Data source: Sorted out from company documents of Haier Ltd. (2005).

In Haier's HAC Sector, there are approximately 13 NPD teams, each composed of 10 to 15 members. According to the compulsory rule in Haier, a new idea regarding product development should be bid for at least by two teams. Teams are composed of volunteer developers, and those with specialized supplemental technologies or cooperating experiences are always the most popular. Of all the core members, a person with strong communicative skills will be elected Model Manager to lead the whole self-organized team, and a person knowing well the new concept of selected product model will be elected model planner. This pre-approved team then starts to prepare for bid, and not until their winning can the team be formally established and the Model Manager be officially appointed.

If succeeding in the bid, the team will be devoted immediately to new product development process defined by a "T-n (days)" schedule. Put it in details, in the "T-90" (i.e. a three-quarter budget), all team members will take part in every development stage such as project planning, product design and product test. In the "T-180" (i.e. a half-year budget) which is supervised by the planning department director, both module developers and model manager are involved in such stages as new idea development, feasibility analysis and product alternatives projecting. They will also work out their own team's project plan accordingly. In the long-term "T-360" (i.e. a three-year rolling budget) which is supervised by the product sector director, after the overall R\&D objective as well as market positioning are defined by participants from planning, marketing and financial departments, the director of R\&D department will join in the following 
analyses of 1) product portfolio, 2) market competition, and 3) product development directions. Candidate model managers will participate in Stage 2, and module developers plus the director of quality department will be added in Stage $3^{4}$.

As can be seen from "T-n" schedules, although payments to R\&D personnel mostly stem from short-term "three-quarter innovations", model developers, or core members of NPD teams, are widely involved in such forward-looking activities as product strategic planning and product design planning. This arrangement enables product planning personnel to join NPD teams as model planners and share their teams' profits. And directors of Product Sectors can thus concentrate more on long-term (over three years) innovations. Through the interlocked participation in various "T-n" schedules, technological specialists in Haier are oriented towards a balance between serving current market demands and creating future competitive advantages.

NPD teams should take end-to-end responsibility for their product designs even after their products are put into market, thus they actively collect market information and try to build their NPD activities exactly on customer needs to minimize losses during manufacturing, promotion and even post-selling. Model managers tend to keep close formal or informal relationships with product managers of local outlets so as to persuade them to order their newly developed products. Given the desires to provide leading solutions to customer complaints, model managers are also empowered to search for needed personnel from outside their own product sectors or even outside Haier Group. A variety of experts are invited by the R\&D departments to work on related projects and get paid in the form of "project cost", and the intellectual property rights of all technical achievements belong to Haier. To conclude, cross-functional membership of NPD teams and cross-boundary relationships within or outside the Product Sectors not only broaden the sources of information but also benefit in the flow-in of diversified knowledge.

\subsection{Composition and structure of knowledge within NPD teams}

NPD teams in Haier are expected to possess a knowledge system of know-why, know-what, know-how and know-who. Refrigeration cycle system of air conditioners integrates compressor, condenser, expansion valve (or other restricting elements) and evaporator, of which compressor is the heart but can

\footnotetext{
${ }^{4}$ In Haier, experts outside the focal product sector are continuously invited to participate in the analysis of market competition and product development directions in the "T-360" process as well as in the complete "T-180" process, which provides a wider horizon adopted in the early stages of NPD activities.
} 
function well only while assembled with other elements together. Thus the fit between different components is crucial for satisfactory solutions to customer demands. This kind of knowledge, namely know-why, which represents an understanding of the principles underlying the construction of each component and the interactions between them, comes from repeated experiments and simulations with different parameters, or so-called process of learning-by-studying (Dutton and Thomas, 1985). To equip Haier's air conditioner development teams with sufficient know-why, model developers and back-up managers are all required to be "junior college graduators or above" with at least "two-year tenure" and "familiar with new product development process, majoring in cooling, heating and ventilating, mechanical or electrical engineering" (see Table 1).

Products or technical systems are always purchased for special applications, and customers should know exactly what problems the products or systems purchased can or can not solve. This kind of knowledge comes from the learning-by-using process, which is referred to as know-what. It represents an understanding of what specific system configurations needed by different consumers for different usages. While some know-what is explicit and can be coded, transmitted, stored and shared, the other is tacit and therefore can only be grasped by those with sufficient experiences, skills and professional knowledge and in close contact with customers. Hence it is common in the "T-180" process that the director of planning department will bring marketing personnel, model managers, module developers and other experts together to analyze field incident rates and selling points of new products so as to better satisfy customer demands. Whenever a new functional model is available, the director of planning department will initiate several customer tests and initiate immediate refinements according to any reported defects until the product fulfils targeted customers' demand. What deserves special attention is that team's bide-winning will be trained at the very outset of every "T-90" process to assure their in-depth understanding of the entire demand-oriented project.

For the sake of reaching expected product functions, R\&D personnel are also involved in the process of learning-by-doing and obtain know-how which represents an understanding of how to manufacture each component and how all components should be put together to perform as a system. This kind of knowledge results from accumulation of experiences and reflects the effect of a learning curve. At least two stages of NPD process can contribute to acquisition of know-how: 1) the development stage. NPD teams can borrow ideas from accomplished developments of similar products. Owing to the high mould costs (millions of Yuan), NPD teams must at first produce prototypes manually to find out potential problems in the following mould sinking and their corresponding 
solutions, and then continue with mould development, process description, sample experiments, simulated customer experiments and HR certification. All requires a great amount of experiences, and is of great importance to the zero-defect development at relatively lower model-induced costs. 2) the prior production and production stage. Both small- and large-scale productions exhibit obvious learning curves. While practices in the development stage help to collect experiences of new model development, accumulation of producing skills in the production stage is based on amounts of physical products.

New product development is a process of creating new technologies or new combinations of technologies for customers. Thus know-who ${ }^{5}$, which represents an understanding of who the targeted customers are and from whom to obtain required capabilities, is of great value for NPD teams. In particular, knowing "who knows whom" is also important when technical knowledge is acquired indirectly from brokers. For example, while nearly all the product sectors are busy collecting information of emerging markets, the Business Promotion Sector finds its role in positioning and integrating all internal resources, namely acting as a bridge between clients and Haier's various suppliers. It sets up an engineering department to develop market channels for all engineering products. In summer of 2006, in the Beijing market, while product managers of commercial air conditioners acquired 18 pieces of engineering information, personnel in this newly established engineering department acquired 22, of which only one piece overlapped. Shared information from Business Promotion Sector made the Commercial Air Conditioner Sector far better informed of market trends and more focused on their product development activities. These cooperative effects quickly spread, and managers in other product sectors started to regard the engineering product sale service personnel in the Business Promotion Sector as a helpful bridge-maker to collect and transmit market information, quite different from the traditional pattern which simply relies on their own product managers for information.

Owning a system of know-why, know-what, know-how and know-who is not enough for NPD teams to perform effectively, and a proper portfolio of knowledge among team members also matters a lot. While module developers usually devote their efforts to develop and utilize know-how, model managers should be able to integrate all the modules into a functional system. Their architectural knowledge regarding the whole system includes: how to assemble a set of modules of components (know-how), why certain interactions among modules of components would produce certain functionalities (know-why), and

\footnotetext{
${ }^{5}$ More generally speaking, know-how knowledge refers to that of indirect access in the knowledge network that the focal agent (a node) is in, and these nodes can either be people or technologies (such as modules or standardized components).
} 
what kinds of configuration producing specific functionality would be preferred by targeted customers (know-what). However, it is really not easy for a model manager to be well equipped with all the know-how, know-why and know-what needed. When faced with the impossibility to possess the architectural knowledge systematically, model managers are inclined to give up some decision responsibilities and intentionally break the principle of rewarding team members on the basis of their contributions. Instead, they tend to stabilize "core team members" and improve interpersonal relationships within the teams, so as to better solve the problems in interfaces of modules.

Meanwhile, NPD teams try to integrate ideas and resources from all over the world with the philosophy of "making ourselves more attractive to potential cooperators through autonomous innovations and exchanging for more qualified external resources". For instance, home air conditioner development teams once expected to gain supports from Company $\mathrm{S}$, a prestigious Japanese provider of compressor, but it was always unwilling to provide enough high-quality compressors to Haier. Things changed in 2005, when revenue from newly introduced healthy air-purifying air conditioners climbed over ten million Yuan. Company S suddenly changed its mind and displayed great initiatives in providing Haier with competitive resources.

Besides the efforts to attract powerful global providers and retailers, cooperation between NPD teams in different product sectors as well as with corporate research institutions and eight global design centers is also greatly emphasized. This is why core team members are all required to have strong communication and coordination skills. In contrast to the former "face-caring" philosophy before Haier's market-chain reform, the comprehensive system of "all employees as SBUs" got all NPD teams to realize that they could no longer rely on emotional relationships to obtain needed resources which are now available to those with enough capabilities to solve various existing problems. "In order to exchange for resources from others, you should have something valuable to them." Thus, the principle of "fair deal" underlies both internal and external relationships in Haier. Just as a model manger told us, "People with different interests can get acquainted and understood, and then cooperate with each other. We try to make fair deals come true, but we will not just sit and wait. We must grab resources for ourselves in the context of internal competition encouraged inside our company. And we have to confirm expected cooperators with our own strengths in the belief that we can make profits together and create a win-win situation."

Descriptions above reflect that the basic principle of "fair deal" is now fundamental to relationships between agents in Haier, which results partly from incremental contextual learning of individuals and partly from the "SBU values" promoted by top management. A special department was set up in every product 
sector to develop behavioral norms for market-chain reform. Multi-level technical platforms, including platforms of product information managed by each product sector, and various databases of benchmarking practices, technological modules and standardized components at corporate or group level, have also been established. With these supports, agents as SBUs can easily share cross-model and even cross-product-line and cross-product-sector technologies as well as other resources. And back-up managers with good communication and coordination skills are ready to help NPD teams conveniently acquire knowledge whenever needed. These platforms enable new product developers to conveniently acquire accumulated (explicit) knowledge without knowing exactly "who knows what" (just via searching on platforms or through the help of platform back-up managers). The issue of "knowing who knows what" is then simplified as "knowing where to get what". Since nodes of knowledge network have changed from "who" to "where", skills required to deal with inter-nodal relationships correspondingly change from interpersonal skills to skills of using technical platforms, which adds completely new meanings to "know-how" of relational skills.

In summary, the knowledge structure of NPD teams can be showed in Table 2 . In the following sections, we will discuss the division between exploration and exploitation in more details.

Table 2 Classification of knowledge and heterogeneous composition of knowledge in Haier's NPD teams

\begin{tabular}{|c|c|c|c|c|}
\hline Agents & $\begin{array}{l}\text { Types of know- } \\
\text { ledge }\end{array}$ & $\begin{array}{l}\text { Sources of } \\
\text { knowledge }\end{array}$ & $\begin{array}{c}\text { Patterns of } \\
\text { learning }\end{array}$ & Results \\
\hline $\begin{array}{l}\text { Directors of Plan- } \\
\text { ning dept } \\
\text { Model planners }\end{array}$ & Know-what & $\begin{array}{c}\text { Relationship } \\
\text { with cus- } \\
\text { tommers } \\
\text { Feedback of } \\
\text { customer } \\
\text { demands }\end{array}$ & $\begin{array}{l}\text { Learning-by- } \\
\text { using }\end{array}$ & $\begin{array}{l}\text { Exploration of } \\
\text { product func- } \\
\text { tionalities }\end{array}$ \\
\hline $\begin{array}{l}\text { Model managers } \\
\text { Module deve- } \\
\text { lopers }\end{array}$ & Know-why & $\begin{array}{l}\text { Principles and } \\
\text { theories of } \\
\text { product de- } \\
\text { sign }\end{array}$ & $\begin{array}{c}\text { Learning-by- } \\
\text { studying }\end{array}$ & $\begin{array}{l}\text { Exploration of } \\
\text { product archi- } \\
\text { tecture and } \\
\text { modular tech- } \\
\text { nologies }\end{array}$ \\
\hline Model managers & $\begin{array}{l}\text { Know-who: } \\
\text { a) know who } \\
\text { knows who }\end{array}$ & $\begin{array}{l}\text { Direct or indi- } \\
\text { rect experi- } \\
\text { ences of so- } \\
\text { cial interac- } \\
\text { tions }\end{array}$ & $\begin{array}{r}\text { Learning-by- } \\
\text { networking }\end{array}$ & $\begin{array}{l}\text { Exploration } \\
\text { based on net- } \\
\text { work rela- } \\
\text { tionships }\end{array}$ \\
\hline
\end{tabular}




\begin{tabular}{|c|c|c|c|c|}
\hline Agents & $\begin{array}{l}\text { Types of know- } \\
\text { ledge }\end{array}$ & $\begin{array}{l}\text { Sources of- } \\
\text { knowledge }\end{array}$ & $\begin{array}{l}\text { Patterns of- } \\
\text { learning }\end{array}$ & Results \\
\hline $\begin{array}{l}\text { Model managers } \\
\text { Platform back-up } \\
\text { managers }\end{array}$ & $\begin{array}{l}\text { b) know who } \\
\text { knows what, or } \\
\text { c) know where } \\
\text { exists what }\end{array}$ & $\begin{array}{l}\text { Technology } \\
\text { Modules } \\
\text { Standardization } \\
\text { of compo- } \\
\text { nents and } \\
\text { parts }\end{array}$ & $\begin{array}{l}\text { Learning- } \\
\text { bysubstitu- } \\
\text { tion }\end{array}$ & $\begin{array}{l}\text { Exploitation } \\
\text { based on } \\
\text { modular } \\
\text { technologies } \\
\text { and stan- } \\
\text { dardized } \\
\text { components }\end{array}$ \\
\hline $\begin{array}{l}\text { Model managers } \\
\text { Experimenters } \\
\text { Trial producers }\end{array}$ & $\begin{array}{l}\text { Know-how: } \\
\text { a) development } \\
\text { skills } \\
\text { b) production } \\
\text { skills }\end{array}$ & $\begin{array}{c}\text { Direct working } \\
\text { experiences }\end{array}$ & $\begin{array}{l}\text { Learning-by- } \\
\text { doing }\end{array}$ & $\begin{array}{l}\text { Exploitation } \\
\text { based on } \\
\text { learning } \\
\text { curves }\end{array}$ \\
\hline $\begin{array}{l}\text { Model managers } \\
\text { Model Planners } \\
\text { Platform back-up } \\
\text { Managers }\end{array}$ & $\begin{array}{l}\text { c) human } \\
\text { relational skills }\end{array}$ & $\begin{array}{l}\text { Direct experi- } \\
\text { ences of so- } \\
\text { cial interact- } \\
\text { tions } \\
\text { Capabilities of } \\
\text { using tech- } \\
\text { nical plat- } \\
\text { form }\end{array}$ & $\begin{array}{r}\text { Contextual } \\
\text { learning }\end{array}$ & $\begin{array}{l}\text { Exploitation } \\
\text { based on in- } \\
\text { terpersonal } \\
\text { relationships } \\
\text { or inter- } \\
\text { nodal rela- } \\
\text { tionships }\end{array}$ \\
\hline
\end{tabular}

\section{Discussion}

\subsection{Ambidextrous capabilities developed in diversified NPD teams}

Previous empirical research exhibits that organizational ambidexterity results from ambidextrous context (Gibson and Birkinshaw, 2004). However, the answers to the problem how contexts, or external causes, work through internal factors still remain incomplete in current research. This article bridges the gap by inductively analyzing how cross-functional boundless teams can balance exploration and exploitation, and further creativity and efficiency. As the specific case we study, Haier's air conditioner development section has achieved 176 patents, including 60 inventions, of which the patent "healthy air purifying" was applied to "2007 KFRd", a star product that set a dominant healthy standard in Chinese air conditioner industry. Additionally, the "impeller-tumbling box" washing machine invented by the Washing Machine Sector, as well as the "anti-creepage wall" electric water heater developed by Electro-heating Product Sector which represents the first case that a corporate patent was accepted as a national standard, both indicate Haier's unique capabilities in organizing innovations. 
Teams as economic independent SBUs, characterized by diversity of members and heterogeneity of knowledge, are widely set up in Haier for the sake to motivate autonomous innovations. Intra-team shared market and profit targets, long-term relatively stable cooperating relationships, and cross-functional interactions together help to establish the ambidexterity in both exploration and exploitation. As the last column of Table 2 shows, the spread of explorative and exploitative activities among team members in the process of product new development may be explained by the heterogeneity of knowledge and key connections within and outside teams (as displayed in Fig. 2).

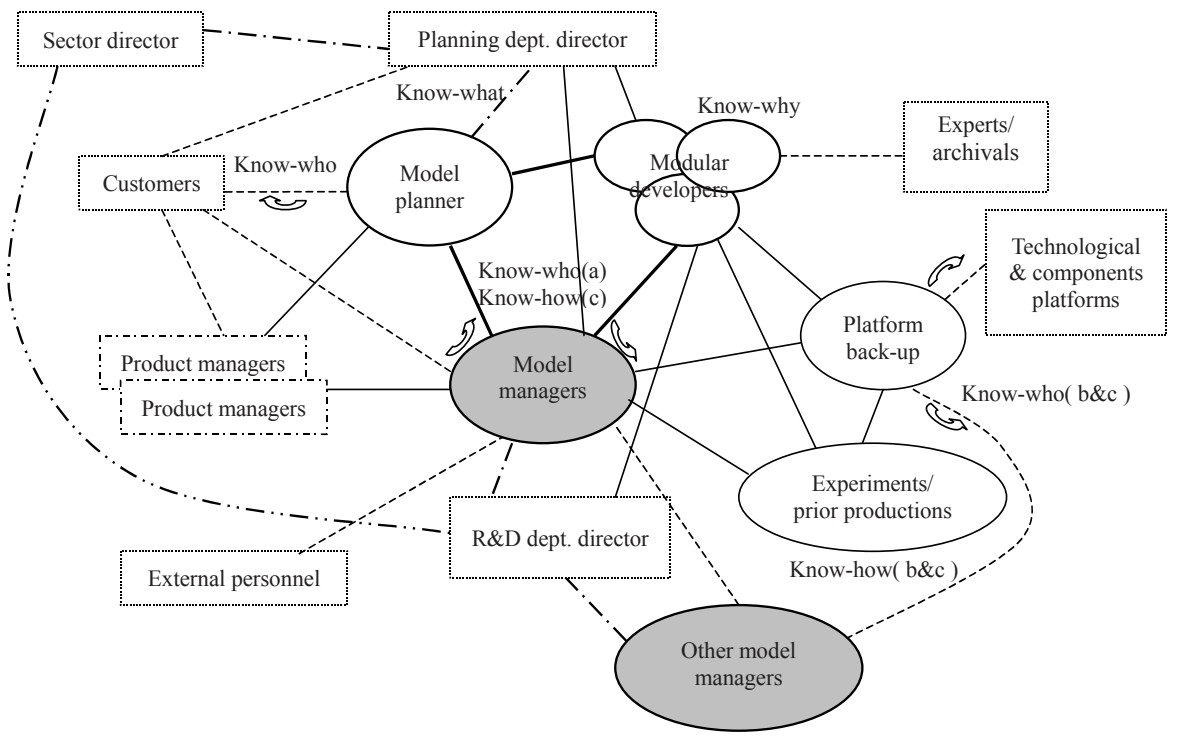

Fig. 2 Heterogeneity of knowledge and key connections in Haier's NPD Teams (Bold arrows represent requirements for human relational skills)

As noted in the case of Haier's home air conditioner development, core team members including model managers and their long-term cooperative model planners and several modular developers, exhibit a high level of insights and creativity in exploring new functionalities and architectures of as well as new technologies and materials used for the products under the course of development by the means of learning-by-networking, learning-by-using and learning-by-studying. The R\&D assistants, at the meantime, make good use of intra-sector or intra-corporate knowledge through learning-by-substituting alternative modules of technologies and/or components and learning-by-doing by virtue of learning curve effects at the stages of prototype development, experiments, prior and scale-up production and thus improve efficiency of new 
product development processes.

What is more, all the core members of each NPD team are required to have good skills in communication and coordination, which augments the "know-how" knowledge regarding human relational skills. Therefore, NPD team with diversified members good at social interactions are equipped well not only with "know-why" knowledge regarding the choice of product architectures and the design of modular designs which generally comes from learning-by-studying and "know-how" knowledge (including skills of development and production) resulted from learning-by-doing, but also with the capabilities to acquire "know-what" and "know-who" knowledge, of which the former enables teams to get on-time feedback from customers, distributors and product managers and thus to improve product functionalities, while the latter can help develop human relational skills, or social skills, and relationship-based "know-how". Furthermore, our observations of technical networks and interpersonal networks in the highly-modularized new product development process discloses that the contents of "know-who" knowledge is extending from either "who knows who know what" or "who knows who know others know what" to include a third type concerning "who knows where to get what" or even "who knows how to know who knows that or where there is that".

The emphasis on the inter-personal or inter-nodal relationships mentioned above predicts the types of knowledge acquired by the NPD teams in Haier and explains clearly why agents with strong market target incentives could simultaneously devote to both explorative and exploitative activities. Since members initiating connections outside the team tend to be diversified, far less redundant ties are likely to take place in the cross-functional teams than in others, and the flow-in of knowledge tends to be heterogeneous. At the same time, due to the strong and friendly intra-team connections are deliberately developed and maintained by model managers (see below) and in the boundless operations, the team members show high probability to share their diversified and heterogeneous knowledge at hand. Hence, the characteristics of team composition and the internal and external relationships of NPD team can be antecedents of ambidexterity.

\subsection{Multi-level ambidexterity realized under specific conditions}

Zhu et al. (2006) described that "market-chain reform in Haier has met with general acceptance all over the world. Examinations of its reengineered business processes show that $R \& D$ is only treated as a supporting process while marketing (Business Promotion) as a core one. There exists no formal cooperating mechanisms between technical innovations and market creation, although the two are functionally integrated to some extent in the sense that market information is introduced into R\&D activities, and innovations are employed to 
back up promotion of new products. Internal market in Haier led to relations of market exchange between $R \& D$ and marketing departments...Treating $R \& D$ process as a supporting one is not propitious for further formation of the corporate culture regarding technical innovations as critical to the overall value creation. It may also induce the adoption of business strategy toward marketing-centered activities rather than the development of core technical capabilities in the long run."

However, our examination of the case in Haier goes against with the thesis above. In fact, model managers who take end-to-end responsibilities for the entire NPD process and their leading "SBU" teams, plus the entitling of directors of R\&D department as "medium model managers" and directors of product sectors as "large model managers" represent that new product development process has gained its position of "core" ones responsible for order creation, while business promotion process has been devalued as supporting process to provide marketing platform for product sectors as their internal customers. In this new business system, product sector directors, R\&D department directors and model managers are respectively high-level, middle-level and low-level model managers (also known as "three-grade (S-B-U) key managers" in their different span of responsibilities for corresponding large, medium or small markets). ${ }^{6}$

As described in the case, since purchasing and selling in Haier are consolidated from functional divisions and operated centrally at the corporate level, while manufacturing functions are organized within product sectors in the form of OEM, it appears that designing, manufacturing and selling are grouped separately from one another, and the corporate organizational structure looks similar to ordinary functional types (i.e., U-form). However, a fundamental distinction is observed in our case study. That is, while R\&D personnel in U-form organizations are involved solely in designing of new products with little consideration of the following manufacturing and selling and thus are inclined to concern more for their superior's directives rather than market performance of the product, the SBU system in Haier puts forward rigorous demands on NPD teams led by "small model managers" and guided by higher-level directors as "medium" or "large" model managers take the entire R\&D process into consideration. Thus they should, in addition, be responsible for whether or not their newly developed products be successful on the targeted markets. CEO

\footnotetext{
${ }^{6}$ As noted by Haier's CEO, Zhang Ruimin, "Nowadays, what our product sector directors care more is to create orders rather than to supervise the subordinate divisions. He should care more about how many orders his sector could get. There are a dozen of model managers who are under his leadership, and he performs as a 'large' model manager, similar to the role of lower-level model managers. Compared with 'small' model manager who is in charge of one or two models of product, higher-level model manager may be in charge of over 10 models and should take the responsibility to cultivate capable lower-level model managers."
} 
Zhang Ruimin provided an excellent articulation of the logic supporting "SBUs": on one hand, the corporation supports new product development by improving resource platforms; on the other hand, managers in different product domains compete with each other to "grab resources". As for the reason of grabbing resources, Zhang explained that "because of the undeniable scarcity of resources, integration of resources provided by others is no longer sufficient for excellent performance. The more resources others grab and integrate for their projects, the less are left for you. Thus, great efforts are required for every SBU in order to acquire needed resources in the face of competition and to achieve targeted market performance." It is the highly competitive resource-acquisition process that puts strong pressure on Haier's NPD teams to grab any needed resources through both inter-personal and inter-nodal networks which provides access to actors or nodes with heterogeneous knowledge.

Driven by the situational prerequisites created by Haier's top management and backed up by the modular nature of household appliances as well as promoted by the strong human relational skills of R\&D personnel, Haier's capabilities in developing innovative products in an efficient way create a virtuous cycle for drawing more and more qualified suppliers to be linked together in Haier's NPD networks.

Upon the various connected nodes and based on a seemingly functional structure, another crucial question exists why Haier can maintain an integrated R\&D process which ranks high at both efficiency (e.g., short development period, low R\&D cost) and creativity (e.g., product innovations). In addressing this question, we would argue that each level of model managers in the SBU system is now an organizer of NPD processes. Innovative agents and model managers play significant roles in organizing innovation. Sigelkow and Rivkin (2006) found, in their multi-agent simulation of CAS, that empowerment of exploration to lower levels does not necessarily result in better organizational-level performance. As Gupta et al. (2006) commented, only when all the departments are loosely coupled are lower-level agents allowed to focus on exploration without the need to preserve equilibrium between exploration and exploitation. However, according to our case study in Haier, the picture has changed. After the market-chain reform, product sectors and their subordinate $R \& D$ departments are obliged to cooperate closely with other core and supporting process units, hence the whole organization is actually tightly coupled. In this organizational architecture, the market-performance motivated NPD teams led by model managers can successfully achieve their ambidextrous state of innovation at lower organizational level, which may aggregate to form a higher level organizational ambidexterity. For example, directors of development department as the so-called "medium" model mangers may become middle-level ambidextrous agents in the manner to cultivate their subordinate "small" model 
managers. Similarly, directors of product sectors as the "large" model mangers may become high-level ambidextrous agents whose responsibility is composed of their cultivated "medium" model mangers who actively balance the explorative and exploitative activities in the new product development processes under their charge.

\subsection{Full empowerment and moderate use of powers}

As Reagans and Zuckerman (2001) suggested in their social network analysis on innovation networks, strong ties within R\&D teams facilitate cooperation and collective actions, while structural holes (weak ties) outside teams provide diversified and non-redundant information. Thus, interaction of different types of relationships can exert significant positive influence on R\&D performance. By further introducing organizational tenure as a measure of diversity of R\&D personnel, Reagans and Zuckerman (2001) proved that frequent contacts with those who differentiate in organizational tenure are more helpful to $R \& D$ performance than contacts with those with similar organizational tenures. This conclusion can be interpreted in terms of that heterogeneity of membership brings distinct skills, information and experiences, and thus improves creativity of R\&D teams. However, how strong ties in place of weak ones or structural holes can be established within teams with diversified membership remains unclear in existing literatures. Also, although a better measure than demographic variables, organizational tenure can not catch explicitly the full meaning of heterogeneity of team members.

To make some contributions to current management theories, types of knowledge of team members are employed to measure heterogeneity of NPD team in Haier case. Different from the common inclination that people favor interacting with those of the same characters, which generally leads to formation of strong ties, in Haier's NPD team which are motivated by thoroughly result-oriented incentive system, a preference to establish stable long-term cooperating relationships with heterogeneous members are consistently observed across several product development projects. Even though model managers are authorized with the power to make "four decisions", including decision on who to involve in the project, and are encouraged to distribute team profit in proportion to individual contributions, to our surprise, they seldom exercise their powers to change either team members or the proportion of profit sharing. Our survey shows with reliability that, in the HAC Sector and the Electro-heating Product Sector, both the membership of core developers and the percentage of team profit distribution for each member remain unchanged across dozens of projects. Then, does the lack of powers use stem from non-utilization of the so-called system of "SBUs" and "thorough result-orientation"? Or is it because 
that model managers are making contingent rational decisions as the case might be, so as to build up stable foundations for long-term cooperation within relatively stable teams?

As described above, model manager is a temporary post for whom wins the bid for a NPD project. Since no payment until their designs are successfully turned into orders, model managers and their teams are thus compelled to take end-to-end responsibility for the entire development process. This result-based mechanism makes clear everyone's rights and liabilities, and reinforces empowerment at lower organizational levels. For the sake of keeping some familiar personnel together to promote smooth cooperation, model managers generally prefer to employ their powers moderately. Long-term relatively stable cooperation helps NPD teams grab scarce heterogeneous resources and develop competitive new products. As such, when unity of full empowerment and moderate use (disuse) of powers is in place, a diversified team can excel at both external non-redundant ties and internal strong ties, while it is generally more difficult for teams with homogeneous members. Owing to model managers' prudent and rational use of power, NPD teams with heterogeneous knowledge can hold diversified members together with strong ties and maintain long-time stable cooperation. At the same time, non-redundant information or other resources from various external linkages are internally transferred and shared. This is why NPD teams in Haier can lend themselves to a unique balance between exploration and exploitation.

\section{Conclusions}

Taken together, previous findings and the case-based qualitative study in Haier provide some revealing ideas. Firstly, ambidexterity is not limited to organizational level. It is a construct valid probably at various levels of model managers, teams, product sectors, as well as organizations. Our case study corresponds to some previous research (Adler et al., 1999; Gupta et al., 2006) which explicitly embrace the idea that exploration and exploitation are not two ends of a continuum or orthogonal to each other, but two dimensions of the same construct that can get reconciled. Furthermore, different from the viewpoints of spatial separation, our findings suggest that individuals and groups capable to pursue simultaneously exploration and exploitation may be proper units of analysis in addition to the traditionally focused organization level of analysis. Thus, the construct of ambidexterity may be applied to various levels, and its meaning is extended from "dual structures" observed merely at organization level to "ambidextrous capabilities" which may be valid at the lower levels of 
organizations.

Secondly, as our study reflects, the capabilities of lower-level agents to balance exploration and exploitation stem not only from ambidextrous context (Gibson and Birkinshaw, 2004), but also from integration of intra-team heterogeneous knowledge. In Haier, while NPD teams which are motivated by SBUs system prefer forming strong internal ties within relatively stable membership, heterogeneity of knowledge resulted from diversified team members promotes the establishment of weak but non-redundant external ties, plus the gradually improved skills of know-who as well as know-where of team members, the NPD teams show consistently their capabilities to realize ambidexterity at lower organizational level. This article contributes to our understanding of paradox in general, and ambidexterity in the innovation process in particular, from philosophic thinking to a more operational angle by bringing to light the strategies and means for achieving reconciliation of two dialectical dimensions.

Building on classifications of knowledge, we illustrate that heterogeneity besides demographic characteristics lends us a good insight into the influence of diversity on network configurations (Reagans and Zuckerman, 2001; Tayor and Greve, 2006). However, inconsistent with some prior research highlighting that heterogeneity leads definitely to weak ties, we find that heterogeneous team members can attract and interact closely with each other (in strong ties) when some conditions which encourage balance of creativity and efficiency are in place. The solid installation of SBUs system, linked to end-to-end responsibilities and market performance, provides strong incentives to core team members with strong technical and human relational skills to cooperate and optimize their collective actions. This enables heterogeneous team members to perform well in developing external ties, acquiring external knowledge and share non-redundant knowledge with each other within the teams. With the ambidexterity aggregating from lower-level agents cultivated to autonomous innovations, Haier is hence equipped with ambidextrous capabilities to realize simultaneously the twin competence of differentiation and low-cost in the a highly competitive global market.

\section{Future research}

Study examining exploration and exploitation at a micro level is relatively scarce. Hence this article tries to add a fillip to research by illustrating why and how micro-level ambidexterity can be established. Future attempts can be made to compare the feasibility and appropriateness of micro-level ambidexterity in 
different contexts (including both external and internal factors). Also, study that addresses the question such as the following has the potential to fill important gaps: Why in some special cases can ambidexterity only be achieved at organization level? Is it because that organizations or managers always try to adapt to environments at the minimum level for the sake of economizing? Or is it because that internal contexts promoting emergence of ambidexterity are not well established? If the answer to the last question is yes, we can expect that top management can still plays a key role directly in building organization ambidexterity even when they are not direct integrators in dual structures. In sum, research on the transformed roles of top management and different internal and external contexts are necessary and important for in-depth understandings of ambidexterity.

Acknowledgements This study is supported by the Humanities and Social Science Program of the Ministry of Education of PRC (No. 08JA630086) and the National Natural Science Foundation of China (No. 70571082). The authors would like to thank Haier Ltd. for the support of the survey and interviews. Special credits belong also to Prof. Li Zhanxiang, former research supervisor of the first author, for his early training and continuous encouragement on dialectic analysis of "Maodun" (or contradiction). In particular, a special thank goes to Prof. Wenpin Tsai in Smeal Business School, Pennsylvania State University, for his kind invitation of the first author as a visiting scholar there and being the driving force for this case-based qualitative research. Without his persistent suggestions to utilize the Oriental perspective in dealing with paradox, this project could not have been as extensive as it is now.

\section{References}

Adler P S, Goldoftas B, Levine D I (1999). Flexibility versus efficiency? A case study of model changeovers in the Toyota production system. Organization Science, 10(1): 43-68

Benner M J, Tushman M L (2003). Exploitation, exploration, and process management: The productivity dilemma revisited. Academy of Management Review, 28(2): 238-256

Birkinshaw J, Gibson C (2004). Building ambidexterity into an organization. MIT Sloan Management Review, Summer: 47-55

Bouchikhi H (1998). Living with and building on complexity. Organization, 5(2): 217-232

Brown S L, Eisenhardt K M (1997). The art of continuous change: Linking complexity theory and time-paced evolution in relentlessly shifting organizations. Administrative Science Quarterly, 42(1): 1-34

Charles H (1994). The Age of Paradox. Boston: Harvard Business School Press

Christensen C M (1997). The Innovator's Dilemma. Boston: Harvard Business School Press

Daft R L (2003). 组织理论与设计 (Organization Theory and Design). 北京: 清华大学出版社

Dopfer K (2004). 演化经济学: 纲要与范围 (Evolutionary Economics: Program and Scope). 北 京: 高等教育出版社

Duncan R B (1976). The ambidextrous organization: designing dual structure for innovation. The Management of Organization, (1): 167-188

Dutton J M, Thomas A (1985). Relating technological change and learning by doing. In: 
Research on Technological Innovation, Management and Policy, Rosenbloom R S (eds.): 187-224. Greenwich, CT: JAI Press

Gassmann O, Sandmeier P, Wecht C H (2006). Extreme customer innovation in the front-end: Learning from a new software paradigm. International Journal of Technology Management, 33(1): 46-66

Gharajedaghi J (1999). Systems Thinking: Managing Chaos and Complexity: A Platform for Designing Business Architecture. Amsterdam: Elsvier/ Butterworth-Heinemann

Gibson C B, Birkinshaw J (2004). Antecedents, consequences, and mediating role of organizational ambidexterity. Academy of Management Journal, 47(2): 209-226

Gupta A K, Smith K G, Shalley C E (2006). The interplay between exploration and exploitation. Academy of Management Review, 49(4): 693-706

He Z-L, Wong P-K (2004). Exploration vs. exploitation: An empirical test of the ambidexterity hypothesis. Organization Science, 15(1): 481-494

Hoyt J, Gerloff E A (1999). Organizational environment, changing economic conditions, and the effective supervision of technical personnel: A management challenge. Journal of High Technology Management Research, 10(2): 275-293

Kang S-C, Morris S S, Snell S C (2007). Relational archetypes, organizational learning and value creation. Academy of Management Review, 32(1): 236-256

Kedia B L, Keller R T, Jullan S D (1992) Dimensions of national culture and the productivity of R\&D units. Journal of High Technology Management Research, 3(1): 1-18

March J G (1991). Exploration and exploitation in organizational learning. Organization Science, 2(1): 71-87

McDonough E F, Leifer R (1983). Using simultaneous structures to cope with uncertainty. Academy of Management Journal, 26: 727-735

McGrath R G (2001). Exploratory learning, innovative capacity and managerial oversight. Academy of Management Journal, 44: 118-131

Mitroff I (1995). Review of the age of paradox. Academy of Management Review, 20(3): $748-750$

Nonaka I, Takeuchi H (1995). The Knowledge Creating Company. New York: Oxford University Press

Nonaka I (1994). A dynamic theory of organizational knowledge creation. Organization Science, 5(1): 14-37

O’Reilly C A, Tushman M (2004). The ambidextrous organization. Harvard Business Review, 82(4): 74-82

Perez-Freije J, Enkel E (2007). Creative tension in the innovation process: How to support the right capabilities. European Management Journal, 25(1): 11-24

Poole M S, Van de Ven A H (1989). Using paradox to build management and organization theories. Academy of Management Review, 14(4): 562-587

Reagans R, Zuckerman E W (2001). Networks, diversity, and productivity: The social capital of corporate R\&D teams. Organization Science, 12(4): 502-516

Siggelkow N, Levinthal D A (2003). Temporarily divide to conquer: Centralized, decentralized, and reintegrated organizational approaches to exploration and adaptation. Organization Science, 14(6): 650-669

Siggelkow N, Rivkin J (2006). When exploration backfires: Unintended consequences of multilevel organizational search. Academy of Management Review, 49(4): 779-795

Smith W K, Tushman M L (2005). Managing strategic contradictions: A top management model for managing innovation streams. Organization Science, 16(5): 522-536

Taylor A, Greve H R (2006). Superman or the fantastic four? Knowledge combination and 
experience in innovative teams. Academy of Management Review, 49(4): 723-740

Tushman M, O'Reilly C A (1996). Evolution and revolution: Mastering the dynamics of innovation and change. California Management Review, 38(4): 8-30

Tushman M, O’Reilly C A (1997). Winning Through Innovation: A Practical Guild to Leasing Organizational Change and Renewal. Boston: Harvard Business School Press

鞠强（Ju Qiang）(2003). 二元相对平衡管理理论 (Manage towards dual balance). 企业管理, (11): 95-97

鞠强 (Ju Qiang) (2007). 走进和谐管理一二元相对平衡管理哲学综述 (Manage towards Hexie: A review of the logic of dual management). 企业研究, (2): 9-12

李占祥, 杨杜, 解培才 (Li Zhanxiang, Yang Du, Xie Peicai) (2000). 矛盾管理学 (Contradiction Management Science). 北京: 经济管理出版社

李玉玲 (Li Yuling) (2006). 二元型组织设计与创新流研究 (Ambidextrous organizations design and innovation flow). 吉林大学硕士学位论文

史江涛, 曹兵 (Shi Jiangtao, Cao Bing) (2006). 间断式技术创新的组织困境及突破 (Difficulties of organizing radical solutions and their solutions). 技术经济, (2): 67-68

袁勇志 (Yuan Yongzhi) (2001). 企业创新与企业二元组织结构 (Corporate innovations and dual structures). 南京农业大学学报(社会科学版), (1): 94-98

张洪石, 陈劲 (Zhang Hongshi, Chen Jin) (2005). 突破性创新的组织模式研究 (The study about organizational mode for radical innovation). 科学研究, (4): 566-571.

张蛋 (Zhang Xi) (2006). 技术创新的两难悖论与网络化集群式创新研究(Research on the dilemma of technological innovation and countermeasures). 科学管理研究, (2): 1-4

张玉利, 李乾文 (Zhang Yuli, Li Qianwei) (2006). 双元型组织研究评介 (A review of ambidexterity). 外国经济与管理, (1): 1-8

郑平 (Zheng Ping) (2007). 基于公司创业的破坏性创新研究 (A study on radical innovations based on entrepreneurship). 中国人民大学博士学位论文

朱凌, 许庆瑞, 王方瑞 (Zhu Ling, Xu Qingrui, Wang Fangrui) (2006). 从研发一营销的整合到技 术创新: 市场创新的协同 (Transformation from the integration between R\&D and marketing to synergy between technological innovation and market innovation). 科研管理, (5): 22-30 